\title{
ANALISIS KLASIFIKASI KEPUASAN PENUMPANG MASKAPAI PENERBANGAN MENGGUNAKAN ALGORITMA NAÏVE BAYES
}

\author{
Agung Wijayanto, Januario Freitas Araujo Bernardo, Sapto Pamungkas \\ Program Studi Magister Teknik Informatika \\ Univesitas Amikom Yogyakarta \\ Email: agung.1179@students.amikom.ac.id, januario.1200@students.amikom.ac.id , \\ sapto.1169@students.amikom.ac.id
}

\begin{abstract}
Abstrak
Dalam dunia transportasi khususnya penerbangan banyak sekali hal menarik yang bisa dianalisa maupun diperbarui, contohnya dalam menilai kepuasan penumpang maskapai sebagai evaluasi maupun mengetahui seberapa besar kepuasan pelanggan dalam menggunakan transportasi penerbangan tersebut. Karena alasan inilah sehingga peneliti akan melakukan penelitian mengenai hal tersebut di atas dengan menggunakan algoritma Naïve Bayes, dimana pengukuran tersebut diukur dengan 16 variabel pengukur dan I variabel respon. Digunakan dataset sebanyak 129.880 record untuk selanjutnya dari dataset tersebut akan dibagi menjadi data training dan data testing, dimana pembagian data tersebut akan dibuat dalam 4 kondisi yaitu $90 \%, 85 \%$, 80\% dan $75 \%$ untuk masing data training dan sisanya adalah data testing sehingga dapat dilihat dari keempat pembagian ini manakah yang memiliki tingkat akurasi yang paling tinggi. Dari proses analisa menggunakan algoritma Naïve Bayes yang dilakukan dengan aplikasi KNime, didapatkan bahwa pembagian data training $90 \%$ dan Data Testing $10 \%$ adalah hasil akurasi tertinggi dengan persentasi akurasi sebesar $81,466 \%$. Dengan hasil ini maka 16 variabel pengukur yang ditetapkan peneliti dapat dijadikan sebagai sebuah acuan untuk mengukur tingkat kepuasan penumpang maskapai penerbangan.
\end{abstract}

Kata kunci-Klasifikasi, Tingkat Kepuasan, Algoritma, Naïve Bayes

\section{Abstract}

In the world of transportation, especially aviation, there are many interesting things that can be analyzed and updated, for example in assessing airline passenger satisfaction as an evaluation and knowing how much customer satisfaction is in using the flight transportation. It is for this reason that researchers will conduct research on the above by using the Naive Bayes algorithm where the measurement is measured by 16 measuring variables and I response variable. The dataset used as many as I29,880 records, then the dataset will be divided into training data and testing data, where the data distribution will be made in 4 conditions, namely $90 \%, 85 \%, 80 \%$ and $75 \%$ for each training data and the rest is testing data so that lt can be seen from the four divisions which one has the highest level of accuracy. From the analysis process using the Naive Bayes algorithm which was carried out with the KNime application, it was found that the sharing of training data was $90 \%$ and Data Testing $10 \%$ was the highest accuracy result with an accuracy percentage of $81.466 \%$. With these results, the 16 measuring variables defined by the researcher can be used as a reference for measuring the level of satisfaction of airline passengers.

Keywords- Classification, Satisfaction Level, Algorithm, Naïve Bayes

\section{PENDAHULUAN}

Seiring dengan perkembangan zaman di era Industri 4.0 setiap maskapai memiliki cara atau standar kualitas pelayanan yang berbedabeda. Semakin baik cara atau standar kualitas pelayanan sebuah maskapai, maka kepuasan penumpang akan meningkat dan minat calon penumpang maskapai penerbangan akan semakin tinggi untuk menggunakan jasanya. Jika minat calon penumpang sebuah maskapai terus meningkat, maka standar kualitas dari pelayanan jasa maskapai penerbangan harus mampu menghadapi beberapa persaing yang semakin kompetitif. Tetapi jika pelayanan maskapai penerbangan dinilai buruk dapat mengakibatkan menurunnya minat penumpang. Analisis kepuasan adalah proses menganalisa hasil ulasan dari pengguna layanan untuk menentukan sebuah opini atau perasaan terhadap suatu layanan secara keseluruhan. Tujuannya sendiri adalah untuk memastikan perilaku atau opini dari seorang yang mengulas dan memberi pendapat dengan memperhatikan suatu topik 
dan aspek tertentu[I]. Pada penelitian ini proses analisis kepuasan penumpang dengan menentukan beberapa variabel dilihat dari berbagai sisi layanan penerbangan, beberapa kriteria / variabel yang menjadi tolak ukur adalah : layanan onboard, ketepatan waktu kedatangan dan keberangkatan, kebersihan, bagasi, dan lainnya. Beberapa teknik yang dapat digunakan dalam proses analisis kepuasan penumpang penerbangan salah satunya dengan menggunakan Algoritma Naïve Bayes. Algoritma ini termasuk algoritma klasifikasi yang cukup populer dan merupakan sepuluh algoritma terbaik didalam bidang data mining. Algoritma Naive Bayes menggunakan teori probabilitas dari cabang ilmu matematika yang digunakan untuk mencari sebuah peluang paling besar dari semua kemungkinan klasifikasi yang didapatkan, dengan melihat frekuensi dari setiap hasil klasifikasi dari data training [2]. Dalam klasifikasi algoritma Naïve Bayes ini, hasil yang diberikan akan ditampilkan sebagai hasil kepuasan penumpang dalam bentuk pernyataan puas dan netral/tidak puas serta menghitung nilai akurasinya dan menganalisa apakah variabelvariabel yang ditentukan peneliti dapat menjadi acuan untuk menilai tingkat kepuasan penumpang maskapai penerbangan.

\section{METODE PENELITIAN}

\section{I Seleksi Variabel Penelitian}

Penelitian ini dilakukan dengan menggunakan data yang diambil dari situs www.kaggle.com pada Airline Passenger Satisfaction dengan data berjumlah 129.880 record dan terdiri dari 16 variabel pengukur dan I variabel respon. Berikut adalah variabel dari data yang akan digunakan.

Tabel I. Variabel Penelitian

\begin{tabular}{|l|l|}
\hline \multicolumn{1}{|c|}{ Variabel } & \multicolumn{1}{c|}{ Informasi Data } \\
\hline Satisfaction & Variabel Respon Kepuasan \\
\hline Gender & Jenis kelamin penumpang \\
\hline Customer Type & Jenis pelanggan \\
\hline Age & Usia penumpang sebenarnya \\
\hline Type of Travel & Tujuan penerbangan penumpang \\
\hline Class & Kelas perjalanan di pesawat penumpang \\
\hline Flight Distance & Jarak penerbangan dari perjalanan \\
\hline $\begin{array}{l}\text { Departure/Arrival time } \\
\text { convenient }\end{array}$ & $\begin{array}{l}\text { Tingkat kepuasan waktu Keberangkatan / } \\
\text { Kedatangan }\end{array}$ \\
\hline Food and drink & Tingkat kepuasan makanan dan minuman \\
\hline Seat comfort & Tingkat kepuasan kenyamanan kursi \\
\hline On-board service & Tingkat kepuasan layanan On-board \\
\hline Baggage handling & Tingkat kepuasan penanganan bagasi \\
\hline Checkin service & Tingkat kepuasan layanan Check-in \\
\hline Inflight service & Tingkat kepuasan layanan dalam pesawat \\
\hline Cleanliness & Tingkat Kepuasan Kebersihan \\
\hline Departure Delay in Minutes & Menit penundaan saat keberangkatan \\
\hline Arrival Delay in Minutes & Menit penundaan saat Kedatangan \\
\hline
\end{tabular}

Dari variabel di atas, data akan dibuat dalam bentuk excel atau menggunakan format CSV agar bisa diolah dan dianalisa dalam aplikasi Knime atau sejenisnya.

\subsection{Preprocessing Data}

Sebelum data digunakan untuk tahapan analisa klasifikasi, dataset harus dilakukan data preprocessing yang nantinya meliputi : pembersihan data yang tidak lengkap (missing value), transformasi data, dan konversi data agar dapat digunakan pada tahap klasifikasi.

\subsection{Split Data Training dan Testing}

Pada tahap ini akan dilakukan pembagian dataset menjadi 2 bagian yaitu data training dan data 
Agung Wijayanto, Januario Freitas Araujo Bernardo dan Sapto Pamungkas. Analisis

Klasifikasi Kepuasan Penumpang Maskapai Penerbangan Menggunakan Algoritma Naive Bayes

test dengan 4 kali pembagian persentase yang yang didapat sehingga hasilnya akan optimal. berbeda untuk membandingkan hasil akurasi

Tabel 2. Persentase Split Dataset

\begin{tabular}{|c|c|c|}
\hline \multirow{2}{*}{ No } & \multicolumn{2}{|c|}{ Persentase Split } \\
\cline { 2 - 3 } & Data Training & $\begin{array}{r}\text { Data } \\
\text { Test }\end{array}$ \\
\hline I & $90 \%$ & $10 \%$ \\
\hline 2 & $85 \%$ & $15 \%$ \\
\hline 3 & $80 \%$ & $20 \%$ \\
\hline 4 & $75 \%$ & $25 \%$ \\
\hline
\end{tabular}

\subsection{Klasifikasi Naïve Bayes}

Data yang telah dipisah menjadi data training dan data test, selanjutkan dilakukan klasifikasi dengan menggunakan algoritma Naïve Bayes. Teorema Bayes dirumuskan sebagai berikut[9] :

$$
P(Y \mid X)=\frac{P(X \mid Y) P(Y)}{P(X)}
$$

Dimana $Y$ merupakan label kelas yang menjadi target klasifikasi dan $X$ merupakan variabelnya. Teorema Bayes dapat diartikan sebagai pembelajaran berdasarkan data latih untuk pembangunan model dari setiap kombinasi $Y$ dengan semua fitur $X$ sehingga kita akan mendapatkan informasi peluang perolehan kelas $\mathrm{Y}$ berdasarkan variabel - variabel $\mathrm{X}$ yang diamati[I0].

Dari proses klasifikasi di atas, selanjutnya dilakukan proses validasi data dimana Validasi adalah proses mengevaluasi dan menginterpretasikan keakuratan hasil model prediksi dari proses klasifikasi[II]

\subsection{Alur Penelitian}

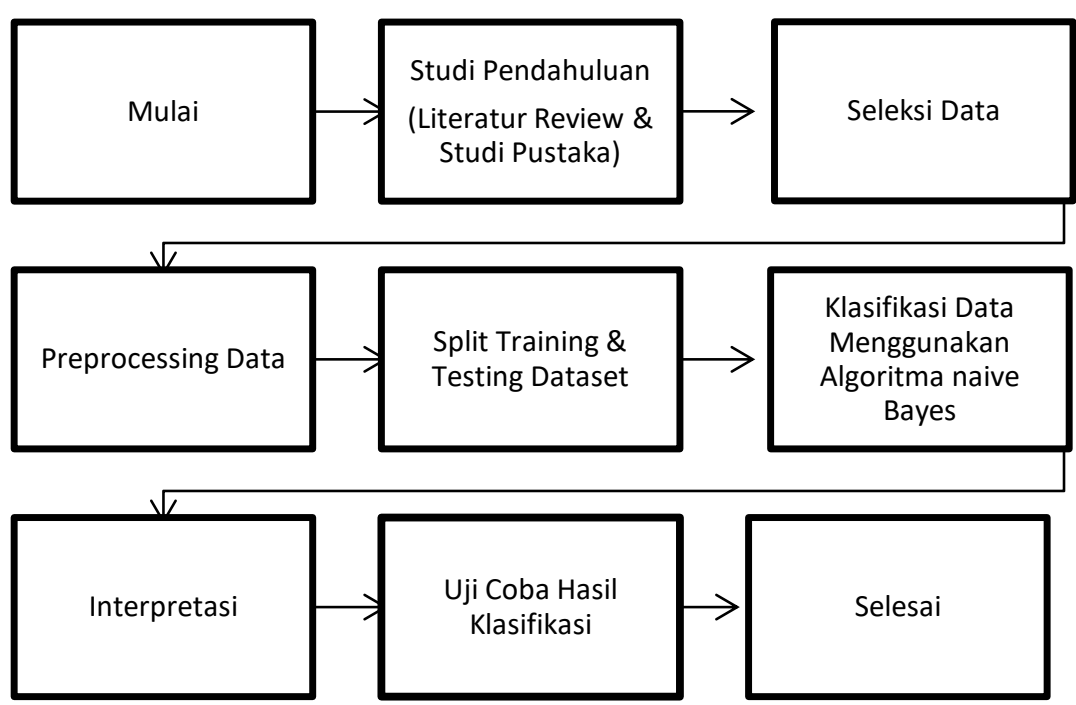

Gambar I. Alur Penelitian

\section{HASIL DAN PEMBAHASAN}




\section{I Tahap Preprocessing Dataset}

Setelah mendapatkan dataset sebanyak 129.880 record, maka tahap selanjutnya adalah melakukan persiapan data untuk selajutnya akan dilakukan analisa klasifikasi dengan cara pembersihan data yang tidak lengkap atau data tersebut kosong. Hasil dari pembersihan data tersebut didapatkan sebanyak 393 data yang

Tabel 3. Variabel dan klasifikasi data penelitian

\begin{tabular}{|l|l|}
\hline \multicolumn{1}{|c|}{ Variabel } & \multicolumn{1}{c|}{ Klasifikasi Data } \\
\hline Satisfaction & Satisfied, Neutral or Dissatisfied \\
\hline Gender & Male, Female \\
\hline Customer Type & Loyal Customer, Disloyal Customer \\
\hline Age & 7-85 Tahun \\
\hline Type of Travel & Personal Travel, Business travel \\
\hline Class & Business, Eco, Eco Plus \\
\hline Flight Distance & $31-4983 \mathrm{~km}$ \\
\hline Departure/Arrival time convenient & Skala $0-5$ \\
\hline Food and drink & Skala $0-5$ \\
\hline Seat comfort & Skala $0-5$ \\
\hline On-board service & Skala $0-5$ \\
\hline Baggage handling & Skala $0-5$ \\
\hline Checkin service & Skala $0-5$ \\
\hline Inflight service & Skala $0-5$ \\
\hline Cleanliness & Skala $0-5$ \\
\hline Departure Delay in Minutes & $0-1592$ Menit \\
\hline Arrival Delay in Minutes & $0-1584$ Menit \\
\hline
\end{tabular}

\subsection{Klasifikasi Data Menggunakan Algoritma Naive}

Bayes Tahap Preprocessing Dataset

Pada tahap klasifikasi ini akan dilakukan pencarian nilai accuracy, precision dan recall

Tabel 4. hasil Split Dataset

\begin{tabular}{|c|c|c|c|c|}
\hline \multirow{2}{*}{ No } & \multicolumn{2}{|c|}{ Persentase Split } & \multicolumn{2}{c|}{ Total Data } \\
\cline { 2 - 5 } & $\begin{array}{c}\text { Data } \\
\text { Training }\end{array}$ & Data Test & $\begin{array}{c}\text { Data } \\
\text { Training }\end{array}$ & Data Test \\
\hline I & $90 \%$ & $10 \%$ & 116.538 & 12.949 \\
\hline 2 & $85 \%$ & $15 \%$ & 110.063 & 19.424 \\
\hline 3 & $80 \%$ & $20 \%$ & 103.589 & 25.898 \\
\hline 4 & $75 \%$ & $25 \%$ & 97.115 & 32.372 \\
\hline
\end{tabular}

Tabel di atas menunjukkan besarnya data yang akan dibagi menjadi data Training dan dataset dari total dataset sebesar 129.487. Selanjutnya adalah melatih semua data training menggunakan algoritma Naïve Bayes sehingga kosong yang berada pada variabel Arrival Delay in Minutes. Jadi total dataset yang sebelumnya sebanyak 129.880 berkurang menjadi 129.487 setelah dikurangi dari 393 data yang kosong . Dari hasil pembersihan data yang kosong, didapatkan informasi dataset yang akan digunakan pada masing-masing variabel: dengan menggunakan algoritma Naïve Bayes dengan pembagian data seperti yang dijelaskan di atas, dimana hasilnya adalah sebagai berikut:

Tabel 5. hasil Klasifikasi Algoritma Naïve Bayes pada DataTest

\begin{tabular}{|c|c|c|c|c|c|c|}
\hline \multirow[b]{2}{*}{ No } & \multicolumn{2}{|c|}{ Persentase Split } & \multirow{2}{*}{$\begin{array}{c}\text { Data } \\
\text { Terklasifikasi } \\
\text { Benar }\end{array}$} & \multirow{2}{*}{$\begin{array}{c}\text { Data } \\
\text { Terklasifikasi } \\
\text { Salah }\end{array}$} & \multirow[b]{2}{*}{ Accuracy } & \multirow[b]{2}{*}{ Error } \\
\hline & $\begin{array}{c}\text { Data } \\
\text { Training }\end{array}$ & $\begin{array}{l}\text { Data } \\
\text { Test }\end{array}$ & & & & \\
\hline I & $90 \%$ & $10 \%$ & 10.549 & 2.400 & $81,466 \%$ & $18,534 \%$ \\
\hline 2 & $85 \%$ & $15 \%$ & 15.802 & 3.622 & $81,353 \%$ & $18,647 \%$ \\
\hline
\end{tabular}


Agung Wijayanto, Januario Freítas Araujo Bernardo dan Sapto Pamungkas. Analisís

Klasifikasi Kepuasan Penumpang Maskapai Penerbangan Menggunakan Algoritma Naive Bayes

\begin{tabular}{|l|l|l|l|l|l|l|}
\hline 3 & $80 \%$ & $20 \%$ & 21.082 & 4.816 & $81,404 \%$ & $18,596 \%$ \\
\hline 4 & $75 \%$ & $25 \%$ & 26.352 & 6.020 & $81,404 \%$ & $18,596 \%$ \\
\hline
\end{tabular}

Dari tabel di atas didapatkan hasil bahwa dengan banyaknya data training yang gunakan sebesar $90 \%$ dan $10 \%$ data test maka hasil akurasinya sebesar $81,466 \%$ dan merupakan nilai tertinggi untuk akurasi yang didapat. Tetapi hasil selanjutnya cukup berbeda dimana dengan pembagian lebih sedikit di data training dan data test yaitu pada pembagian $80 \%-20 \%$ didapatkan tingkat akurasi yang lebih tinggi dibandingkan

Tabel 6. hasil Analisis Klasifikasi pada Split data $90 \%-10 \%$

\begin{tabular}{|l|l|l|l|}
\hline Klasifikasi & Recall & Precision & F-Mean \\
\hline Satisfied, & 0.75 & $0.8 I$ & 0.779 \\
\hline Neutral or Dissatisfied & 0.865 & 0.818 & $0.84 I$ \\
\hline
\end{tabular}

\subsection{Uji Coba Hasil Klasifikasi}

Setelah mendapatkan nilai akurasi yang dinilai paling tinggi, maka tahap terakhir adalah melakukan uji coba pada hasil akurasi tertinggi tersebut dengan menggunakan dataset baru dengan pembagian dataset $85 \%-15 \%$ seperti yang terlihat pada tabel di atas. Dikarenakan nilai akurasi yang didapat adalah berdasarkan pembagian dataset sebesar 90\%-10\%, maka statistik akurasi klasifikasi kepuasan pengguna jasa layanan maskapai penerbangan akan digunakan pembagian terbaik dengan hasil sebagai berikut: :

Tabel 7. Dataset untuk Ujicoba Algoritma Naïve Bayes

\begin{tabular}{|l|l|l|}
\hline \multirow{2}{*}{ Variabel Uji } & \multicolumn{2}{c|}{ Jawaban Dataset } \\
\cline { 2 - 3 } & \multicolumn{1}{c|}{ Datase I } & Dataset 2 \\
\hline Gender & Male & Disloyal Customer, \\
\hline Customer Type & Loyal Customer, & 45 Tahun \\
\hline Age & 23 Tahun & Personal Travel \\
\hline Type of Travel & Personal Travel & Business \\
\hline Class & Eco Plus & $1233 \mathrm{Km}$ \\
\hline Flight Distance & $521 \mathrm{~km}$ & 4 \\
\hline Departure/Arrival time convenient & 2 & 5 \\
\hline Food and drink & 3 & 4 \\
\hline Seat comfort & 3 & 4 \\
\hline On-board service & 3 & 5 \\
\hline Baggage handling & 3 & 5 \\
\hline Checkin service & 2 & 3 \\
\hline Inflight service & 3 & 4 \\
\hline Cleanliness & 4 & 15 Menit \\
\hline Departure Delay in Minutes & 120 Menit & 10 Menit \\
\hline Arrival Delay in Minutes & 30 Menit & \\
\hline
\end{tabular}

Hasil dari ujicoba kedua dataset di atas adalah sebagai berikut:

Tabel 8. Hasil Ujicoba Algoritma Naïve Bayes

\begin{tabular}{|c|l|}
\hline Dataset & Klasifikasi Kepuasan \\
\hline I & Neutral or Dissatisfied \\
\hline 2 & Satisfied, \\
\hline
\end{tabular}




$$
\begin{array}{c|l}
\text { Jurnal Sains Komputer dan Teknologi Informasi } & \text { Page } \\
\text { e-issn : 2655-7460. Volume 3 No.2, Meí 2021 } & 97-103 \\
\hline
\end{array}
$$

Dari kedua tabel di atas, didapatkan bahwa tingkat kepuasan seorang penumpang maskapai penerbangan dapat diukur secara garis besar bahwa maskapai penerbangan wajib meminimalisir keterlambatan penerbangan dengan memberikan kepuasan dari layanan dalam penerbangan terlebih untuk penerbangan dengan jarak yang cukup jauh.

Dari hasil penelitian ini, diharapkan dapat menjadi sebuah referensi untuk mengukur tingkat kepuasan seorang penumpang pada maskapai penerbangan guna terus meningkatkan layanan penerbangan di masa yang akan datang.

\section{KESIMPULAN}

Dari hasil penelitian yang telah dilakukan pada data training dan data set didapatkan hasil bahwa dengan banyaknya data training yang gunakan sebesar $90 \%$ dan $10 \%$ data test maka hasil akurasinya sebesar $81,466 \%$ dan merupakan nilai tertinggi untuk akurasi yang didapat. Tetapi hasil selanjutnya cukup berbeda

\section{DAFTAR PUSTAKA}

[I] A. B. P. Negara, H. Muhardi, and I. M. Putri, "Analisis Sentimen Maskapai Penerbangan Menggunakan Metode Naive Bayes dan Seleksi Fitur Information Gain," J. Teknol. Inf. dan Ilmu Komput., vol. 7, no. 3, p. 599, 2020, doi: 10.25 I26/jtiik.20207| | 947.

[2] S. A. Aaputra, Didi Rosiyadi, Windu Gata, and Syepry Maulana Husain, "Sentiment Analysis Analisis Sentimen E-Wallet Pada Google Play Menggunakan Algoritma Naive Bayes Berbasis Particle Swarm Optimization," J. RESTI (Rekayasa Sist. dan Teknol. Informasi), vol. 3, no. 3, pp. 377-382, 2019, doi: 10.29207/resti.v3i3. III8.

[3] T. H. Apandi and C. A. Sugianto, "Algoritma Naive Bayes untuk Prediksi Kepuasan Pelayanan Perekaman e-KTP ( Naive Bayes Algorithm for Satisfaction dimana dengan pembagian lebih sedikit di data training dan data test yaitu pada pembagian 80\%-20\% didapatkan tingkat akurasi yang lebih tinggi yaitu $81,404 \%$ dibandingkan dengan pembagian dataset $85 \%-15 \%$ yaitu $81,353 \%$. Dikarenakan nilai akurasi yang didapat adalah berdasarkan pembagian dataset sebesar 90\%$10 \%$, maka statistik akurasi klasifikasi kepuasan pengguna jasa layanan maskapai penerbangan akan digunakan pembagian terbaik dengan hasil bahwa maskapai penerbangan wajib meminimalisir keterlambatan penerbangan dengan memberikan kepuasan dari layanan dalam penerbangan terlebih untuk penerbangan dengan jarak yang cukup jauh.

\section{SARAN}

Agar penelitian ini bisa ditingkatkan dan mendapatkan hasil yang lebih baik maka disarankan untuk mempertimbangkan dataset lain dalam penelitian untuk akurasi yang akan dihasilkan oleh Naïve Bayes.

Prediction of e-ID," JUITA (Jurnal Inform. UMP, vol. 7, no. November, pp. I25I28, 2019.

[4] M. Hasan, "Menggunakan Algoritma Naive Bayes Berbasis," vol. 9, pp. 317324,2017

[5] W. D. Septiani, "Komparasi Metode Klasifikasi Data Mining Algoritma C4.5 Dan Naive Bayes Untuk Prediksi Penyakit Hepatitis," None, vol. 13, no. I, Pp. 76-84, 2017, doi:

10.33480/pilar.vI3il.I49.

[6] A. Prabhat and V. Khullar, "Sentiment classification on big data using Naïve bayes and logistic regression," 2017 Int. Conf. Comput. Commun. Informatics, ICCCI 20I7, no. January 20I7, 20I7, doi: I0.1 I09/ICCCI.20I7.8II 7734.

[7] A. D. Poernomo and S. Suharjito, "Indonesian online travel agent 
Agung Wijayanto, Januario Freitas Araujo Bernardo dan Sapto Pamungkas. Analisis

Klasifikasi Kepuasan Penumpang Maskapai Penerbangan Menggunakan Algoritma Naive Bayes

sentiment analysis using machine learning methods," Indones. J. Electr. Eng. Comput. Sci., vol. I4, no. I, p. II3, 2019, doi: I0.II59|/ijeecs.v|4.il.pp||3-II7.

[8] J. Singh, G. Singh, and R. Singh, "Optimization of sentiment analysis using machine learning classifiers," Human-centric Comput. Inf. Sci., vol. 7, no. I, 2017, doi: I0.II86/s13673-017. $0116-3$.

[9] Y. T. Samuel and K. DEwi, "Penggunaan Metode NAIIVE BAYES Dalam Mengukur Tingkat Kepuasan Pengguna Terhadap Online System Universitas
Advent Indonesia," TelKa, vol. 9, no. 02, Pp. 147-153, 2019, doi:

10.36342/teika.v9i02.2162.

[10] H. Oktavianto and R. P. Handri, "Analisis Klasifikasi Kanker Payudara Menggunakan Algoritma Naive Bayes," INFORMAL Informatics J., vol. 4, no. 3, p. I I7, 2020, doi: 10.19|84/isj.v4i3.14I70.

[II] N. Normah, "Naïve Bayes Algorithm For Sentiment Analysis Windows Phone Store Application Reviews," SinkrOn, vol. 3, no. 2, p. 13, 2019, doi: I0.33395/sinkron.v3i2.242. 